\title{
PENGEMBANGAN KEGIATAN POSYANDU LANSIA ANTHURIUM DI SURAKARTA
}

\author{
Yuli Kusumawati, Yulisna Mutia Sari, Siti Zulaekah \\ Fakultas Ilmu Kesehatan \\ Universitas Muhammdiayah Surakarta \\ J1. A. Yani Tromol Pos I Pabelan, Kartasura, Surakarta, Indonesia \\ Email: yuli_kusumawati@ums.ac.id
}

\begin{abstract}
ABSTRAK
Pembentukan masyarakat sehat secara mandirimerupakan program kesehatan masyarakatyang harus terus digerakkan dan dibina agar masyarakat dapat membentuk perilaku hidup bersih dan sehat (PHBS). Salah satuupayanya berupa dorongan kepada masyarakat dalam memantau kesehatan mandiri lansia melalui kegiatan posyandu. Posyandu lansia merupakan bentuk kegiatan yang dilakukan dari, oleh dan untuk masyarakat untuk mendidik dan membina masyarakat, sehingga tercipta masyarakat sehat hingga masa lanjut usia. Posyandu Anthurium terletak di wilayah Surakarta bagian tengah kota dengan karakteristik penduduk sangat beragam dilihat dari sosial ekonominya, namun partisipasi dalam kegiatan kemasyarakatan cukup baik. Beberapa masalah yang masih dihadapiposyandulansiaanthurium iniadalahbelumadanyapapannamaposyandu yang dapat menarik perhatian lansia untuk datang, belum lengkapnya sarana untukpemeriksaan kesehatan rutin, seperti: tensimeter, timbang badandan kit untukpemeriksaanbiokimiadarahsepertikolesterol, asamurat, gula darah, belum adanya prasarana untuk edukasi tentang penyakit-penyakit degeneratif seperti leaflet dan poster-poster, belum tersedia meja dan kursi untuk memberikan pelayanan konseling. Permasalahan lain yang tidak kalah penting adalah pengetahuan dan pemahaman pengelola posyandu dalam memberikan pelayanan untuk memantau kesehatan lansia masih sangat kurang. Kegiatan pengabdian ini dilakukan dalam bentuk pelatihan pembenahan administrasi posyandu, pengadaan dan menambah peralatan untuk pemeriksaan dan pengontrolan kesehatan lansia, mengadakan peralatan konseling kesehatan berupa leaflet dan poster kesehatan, memberikan pelayanan berupa pendidikan dan latihan fisioterapi untuk mencegah dan mengatasi nyeri punggung bawah dan nyeri lutut. Selanjutnya adalah konsultasi gizi, dan penyuluhan tentang tips hidup sehat pada lansia. Hasil pengembangan kegiatan di posyandu lansia dapat meningkatkan motivasi lansia datang ke posyandu untuk mengontrol kesehatannya, sehingga dapat tercipta masyarakat lansia yang sehat, mandiri dan aktif dan tidak lagi bergantung pada program pemerintah.
\end{abstract}

Kata Kunci: Pengembangan, Posyandu, Lansia

\begin{abstract}
The formation of a healthy society independently is a public health program that should continue to be driven and nurtured in order to people can form a clean and healthy living behaviors (PHBS). One of its efforts is encouraging the community to monitor the health of the elderly through Posyandu activities independently. Posyandu is a form of the activities performed by and for the community to educate and nurture
\end{abstract}


the community, so that it can be reached a healthy society until the elderly period. Posyandu Anthurium is located in the region of Surakarta central part of town with the characteristics of the population is very diverse views of the social economy, but the participation in community activities is quite good.Some problems facing in the Posyandu anthurium is the absence nameplate posyandu to attract elderly to come, not complete tool for routine health checks, such as: sphygmomanometer, weigh and kits for the biochemical examination of blood such as cholesterol, uric acid, sugar blood, the lack of infrastructure for education on degenerative diseases such as leaflets and posters, tables and chairs are not available to provide counseling services. Another important issue is the lacking knowledge and understanding of Posyandu management in providing services to monitor the health of the elderly. Service activities in the Posyandu Anthurium is carried out by training of administrative reform posyandu, procurement and add equipment for inspection and control of the elderly health, equipment in health counseling in the form of leaflets and posters healthcare, providing services such as education and training for physiotherapy to prevent and to treat lower back pain and knee pain. Another activities are nutritional consultation and education about healthy living tips in the elderly. The results of development activities in posyandu is increasing the motivation of elderly people coming to neighborhood health center for controlling their health, so that can be created the healthy, active, independent elderly people, and no longer rely on government programs.

Keywords: Development, (IHC) Posyandu, Elderly

\section{PENDAHULUAN}

Masa lanjut usia atau lansia merupakan sebuah tahap akhir kehidupan yang penting untuk diperhatikan kesehatannya, karena merupakan tahap yang rentan terhadap penyakit. Peningkatan kesehatan lansia terus diupayakan dengan pendekatan promotif dan preventif yang dapat dilakukan dari, oleh dan untuk masyarakat sendiri. Upaya tersebut di masyarakat dilakukan dengan penyelenggaraan Pos Pelayanan Terpadu (Posyandu) lansia. Posyandu lansia merupakan bentuk pelayanan kesehatan yang lebih mengutamakan upaya peningkatan kesehatan dan pencegahan terhadap terjadinya penyakit. Kegiatan posyandu dilakukan untuk pemeriksaan kesehatan rutin, memberikan edukasi dan informasi tentang pencegahan penyakit dengan promosi untuk mengajak lansia untuk menerapkan pola hidup sehat, bukan untuk pengobatan bagi lansia yang sakit. Posyandu lansia adalah pos pelayanan terpadu untuk masyarakat usia lanjut di suatu wilayah tertentu yang sudah disepakati, digerakkan oleh masyarakat dimana usia lanjut bisa mendapatkan pelayanan kesehatan. Kegiatan posyandu lansia menitik beratkan pada upaya promotif dan preventif tanpa mengabaikan upaya kuratif dan rehabilitatif.

Posyandu Lansia Anthurium berada di wilayah Kelurahan Tegalharjo, Kecamatan Jebres, Kota Surakarta, dibawah pembinaan Puskesmas Purwodiningratan. Masyarakat di wilayah ini adalah masyarakat yang komplek. Penduduk lansia yang dilayani cukup banyak, dengan berbagai masalah kesehatan yang dihadapi masyarakat. Posyandu Lansia Anthurium diselenggarakan oleh organisasi perkumpulan ibu-ibu pembinaan kesehajteraan keluarga (PKK) wilayah setempat. Posyandu lansia ini belum memiliki sarana dan prasarana yang memungkinkan untuk pemeriksaan kesehatan rutin. Ruang yang dipakai untuk kegiatan posyandu Lansia Anthurium adalah ruang serba guna yang bergantian dengan kegiatan olah raga tenis, selain itu pengarsipan juga belum terlaksana dengan baik karena tempat penyimpanan arsip atau almari arsip belum ada. 
Meskipun kegiatan di Posyandu Anthurium telah rutin setiap bulan sekali dilaksanakan akan tetapi belum bisa mencakup semua kegiatan yang seharusnya misalnya kegiatan edukasi dan konseling belum bisa dilaksanakan karena belum adanya prasarana untuk edukasi dan konseling. Kegiatan yang sudah terlaksana hanya penimbangan, pengukuran tekanan darah dan pemberian makanan tambahan saja dan selesai, sehingga kegiatannya bersifat monoton. Untuk melaksanakan kegiatan tersebut, maka posyandu lansia ini membutuhkan sarana untuk melakukan konseling, alat untuk pemantauan status gizi, alat pemeriksaan biokimia darah yang selalu digunakan secara rutin dalam kegiatan setiap bulannya untuk mengontrol kesehatan lansia.

Berdasarkan analisis situasi tersebut, maka permasalahan yang dihadapi adalah:

1. Kegiatan di posyandu anthurium selama inibaru sekedarmelakukan penimbangan dan pengukuran tekanan darah, serta Pemberian Makanan Tambahan (PMT), belum dapat melaksanakan kegiatan yang lebih bervariasi dari itu.

2. Posyandu Anthurium belum dapat mencakup semua kegiatan yang seharusnya misalnya kegiatan edukasi dan konseling kesehatan.

3. Posyandu lansia belum memiliki alat untuk pemantauan kesehatan lansia terutama pemeriksaan darah sederhana dan alat timbangan badan yang ada sudah rusak (tidak bisa digunakan)

Secara garis besar, posyandu lansia merupakan kegiatan yang diselenggarakan oleh dan untuk masyarakat, terutama untuk memantau kesehatan lansia di wilayah masing-masing, dimana lansia bertempat tinggal. Usia lanjut mempunyai keterbatasan fisik dan kerentanan terhadap penyakit. Secara alami bertambahnya usia akan menyebabkan terjadinya perubahan degeneratif dengan manifestasi beberapa penyakit seperti penyakit hipertensi, kelainan jantung, penyakit diabetes mellitus, kanker rahim /prostat, osteroporosis dan lain-lain (Depkes RI, 2003).
Pandangan masyarakat umum mengenai lansia masih belum sesuai dan keliru. Sebagian besar masyarakat masih beranggapan bahwa lansia merupakan hal yang alami dan biasa bila lansia seringkali sakit, cepat marah atau emosinya yang mudah curiga pada orang lain. Akibat pandangan yang salah tersebut, seringkali kesehatan fisik mental dan kebutuhan sosial lansia tidak tertangani, selain itu lansia sendiri kurng dapat memanfaatkan pelayanan kesehatan yang ada, karena jarak ke puskesmas yang cukup jauh, tidak ada yang mengantar ataupun ketidak mampuan di dalam membayar pelayanan. Oleh karena itu, posyandu lansia, merupakan upaya kegiatan masyarakat untuk menangani kesehatan lansia.

Posyandu lansia adalah bentuk pelayanan terpadu untuk masyarakat usia lanjut di suatu wilayah tertentu yang sudah disepakati, digerakkan oleh masyarakat dimana mereka bisa mendapatkan pelayanan kesehatan. Posyandu lansia merupakan pengembangan dari kebijakan pemerintah melalui pelayanan kesehatan bagi lansia yang penyelenggaraannya melalui program puskesmas dengan melibatkan peran serta pada lansia, keluarga, tokoh masyarakat dan organisasi sosial dalam penyelenggaraannya (Efendi, 2009).

Posyandu lansia diselenggarakan dengan tujuan untuk : meningkatkan kesejahteraan lanjut usia dengan kegiatan lansia yang mandiri dalam masyarakat, memudahkan bagi lanjut usia dalam mendapatkan pelayanan kesehatan, meningkatnya cakupan dan kualitas pelayanan kesehatan lanjut usia, khususnya aspek peningkatan kesehatan dan pencegahan penyakit tanpa mengabaikan aspek pengobatan dan pemulihan, serta mengembangkan lanjut usia yang aktif dalam melaksanakan kegiatan dengan kualitas yang baik secara berkesinambungan (Depkes RI, 2003).

Posyandu lansia telah diselenggarakan di setiap wilayah pada tingkat rukun warga, namun demikian masih ada kendala bagi setiap lansia untuk aktif datang ke posyandu. Beberapa penelitian menunjukkan bahwa 
kendala bagi lansia untuk aktif ke posyandu antara lain pengetahuan lansia yang rendah tentang manfaat posyandu, jarak rumah ke lokasi posyandu, kurangnya dukungan keluarga dan sikap yang kurang baik dari kader pelaksana dan juga kebosanan terhadap kegiatan posyandu yang monoton atau kurang menarik oleh lansia (Maryati, 2013; Mengko, 2015).

Berdasarkan hal tersebut, agar penyelenggaraan posyandu lansia dapat berjalan lancar dan memberikan pelayanan yang baik bagi lansia, maka tujuan dari kegiatan pengabdian ini adalah membantu mengembangkan kegiatan posyandu, berupa:

1. Menyediakan alat periksa darah sederhana untuk mengontrol kadar kolesterol, asam urat dan gula darah lansia, alat timbang badan dan sarana untuk konsultasi berupa meja kursi, leaflet dan poster kesehatan lansia

2. Memberikan pelatihan pada kader bagaimana cara melakukana pemeriksaan darah dengan alat cek darah sederhana,

3. Memberikan konsultasi gizi tentang pengaturan diit untuk mengontrol kesehatannya terkait penyakit yang diderita meliputi hipertensi, diabetes mellitus, stroke, dan asam urat tinggi,

4. Memberikan pendidikan dan pelatihan tentang cara mengatasi nyeri punggung bawah dan nyeri lutut yang sering terjadi pada lansia.

Setelah pengabdian ini yang meliputi kegiatan-kegiatan tersebut, maka tujuan yang diharapkan adalah:

1. Tersedianya peralatan cek darah sederhana, dan terampilnya kader menggunakan alat tersebut untuk melakukan pemeriksaan darah rutin sesuai kebutuhan lansia.

2. Lansia mendapatkan pelayanan cek darah sederhana untuk mengetahui adanya risiko penyakit hipertensi, stroke, asam urat dan diabetes mellitus.

3. Lansia mendapatkan konsultasi gizi tentang makanan yang boleh dikonsumsi, dihindari dan dibatasi untuk mencegah dan mengendalikan hipertensi, asam urat dan kolesterol

4. Lansia mendapatkan informasi tentang cara mengatasi nyeri punggung bawah dan nyeri lutut.

\section{METODE PELAKSANAAN}

Pelaksanan kegiatan pengabdian masyarakat ini dibagi dalam 3 tahap, yaitu persiapan, pelaksanaan dan penyelesaian. Pada tahap persiapan, kegiatan pengabdian ini dimulai dengan proses koordinasi dengan anggota pengabdian, koordinasi dengan Ketua Posyandu Lansia Anthurium di Purbowardayan, Tegalharjo, Jebres, Surakarta pada Bulan Februari 2016. Pada tahap pelaksanaan, kegiatan pengabdian dibagi 2 kegiatan, yaitu:

1. Pengadaan sarana atau alat-alat yang diperlukan untuk pelaksanaan posyandu lansia. Kegiatan pengadaan sarana dan alat-alat ini dilaksanakan pada Bulan Maret 2016, dengan membuat atau memesan papan nama di masingmasing Posyandu lansia, selanjutnya membeli alat tensimeter, timbangan, alat cek darah sederhana, pembuatan leaflet materi fisioterapi dan leaflet untuk konsultasi gizi serta poster tentang tips hidup sehat dan bugar pada lansia.

2. Pelayanan selama kegiatan posyandu lansia.

Kegiatan memberikan pelayanan pada posyandu lansia ini dilaksanakan sesuai dengan jadwal pelaksanaan posyandu tersebut, yaitu hari Sabtu keempat setiap bulannya, yaitu Bulan Maret, April, Mei, Juli, Agustus, September 2016.

\section{HASIL DAN PEMBAHASAN \\ PELAKSANAAN KEGIATAN}

1. Pengadaan sarana atau alat-alat yang diperlukan untuk pelaksanaan posyandu lansia

Kegiatan ini pengadaan sarana dan alat-alat ini dilaksanakan pada Bulan Maret 2016, dengan membuat atau memesan papan nama di masing-masing posyandu lansia dan diserahkan pada ketua posyandu untuk 
dipasang, seperti pada gambar berikut:
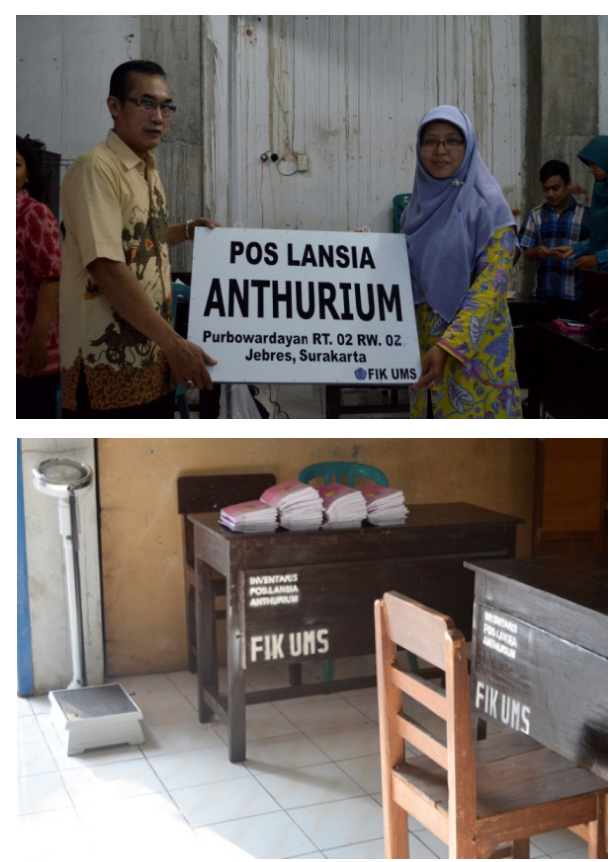

Gambar 1. Penyerahan papan nama Posyandu Lansia Anthurium

Selanjutnya pembelian sarana untuk posyandu lansia Anthurium, yang meliputi Meja konseling 3 bulah dan kusi konseling 6 buah, timbangan badan dan ukur tinggi badan 1 buah, alat ukur tekanan darah otomatis merk Omron Type 7203 sebanyak 1 buah dan alat test darah sederhana merk Nesco GCU sebanyak 1 buah dan diserahkan kepada Posyandu Lansia Anthurium pada hari Sabtu 19 Maret 2016, jam 16.00 WIB.

\section{Pelayanan selama kegiatan posyandu lansia}

Kegiatan pengabdian tahap 2 ini, berupa pemberian kegiatan tambahan berupa penyuluhan kepada lansia. Kegiatan ini dilaksanakan pada saat kegiatan posyandu lansia, yaitu disesuaikan dengan jadwal pelaksanaan posyandu yang sudah berjalan, yaitu : Setiap Sabtu pertama di Posyandu Lansia Anthurium. Adapun kegiatan yang dilakukan pada tahap ini yaitu:

a. Pemberian pendidikan fisioterapi untuk para lansia

Pendidikan kesehatan fisioterap merupakan salah satu bentuk strategi untuk merubah perilaku seseorang lansia, salah satunya perilaku gerak tubuh yang salah, namun sering dilakukan oleh lansia sehingga berisiko terjadinya cidera atau keluhan sendi. Berdasarkan survei yang dilakukan tim pengabdian dan wawancara terhadap lansia, masih banyak ditemukan kurangnya pemahaman tentang penyakit degeneratif, salah satunya adalah Osteoarthritis. Selain itu, diberikan juga pendidikan dan latihan tentang mengurangi nyeri punggung bawah dan lutut.

b. Pemberian pendidikan dan konseling gizi untuk lansia

Pendidikan gizi sebagai salah satu bentuk upayadalammerubahperilaku seseorang, mulai dari merubah pemahaman tentang jenis makanan yang sehat. Berdasarkan survei dan wawancara yang dilakukan tim pengabdian, masih ditemukan kurangnya pemahaman lansia tentang jenis makanan yang perlu dikurangi ataupun perlu dihindari untuk mencegah penyakit degeneratif seperti hipertensi dan diabetes mellitus, juga memberikan konseling tentang pola makan yang sehat untuk penderita hipertensi dan DM. Disamping itu, pihak kader kesehatan pengelola pos lansia belum mengetahui cara memberikan informasi tentang jenis dan pola makan yang baik untuk lansia terutama bagi penderita hipertensi dan DM.

\section{A. Gambaran Umum Pos Lansia Anthurium Sebelum pengabdian \\ Pos LansiaAnthurium berdirisejak Tahun} 2000 pada awalnya merupakan perkumpulan lansia yang hanya sekitar 10 orang, selanjutnya oleh pengurus kader kesehatan balita, didirikanlah pelayanan kesehatan lansia untuk memeriksa kesehatannya, dan dengan adanya program puskesmas santun usia lanjut, perkempulan tersebut mendapat bimbingan untuk memberikan pelayanan kesehatan lansia, untuk mengontrol kesehatan lansia agar lansia lebih sehat, bugar, mandiri. 
Pos Lansia Anthurium beralamatkan di Purwodiningratan, Tegalharjo RT 02 RW 02 Jebres Surakarta. Pos lansia ini sekarang melayani sekitar 80 lansia. Pelayanan Posyandu lansia dilaksanakan di gedung serbaguna milik warga setempat, sehingga peralatan yang digunakan hanya berupa meja dan kursi yang bergantian dengan kegiatan warga yang lain. Pengetahuan dan pehamanan kader pengelola dalam penyelenggaraan pos lansia juga masih kurang.

\section{B. Hasil Pelaksanaan Pengabdian}

Kegiatan pengabdian ini pada prinsipnya adalah untuk meningkatkan dan mengoptimalkan upaya pelayanan kesehatan lansia yang diselenggarakan dari, oleh dan untuk masyarakat sebagai bentuk upaya pemberdayaan masyarakat dalam bidang pembangunan kesehatan.

Dimana posyandu lansia berfungsi sebagai:

1. Pelayanan kesehatan dalam bidang promosi: dimana kegiatan yang dilakukan adalah mengajak dan mempromosikan perilaku hidup sehat

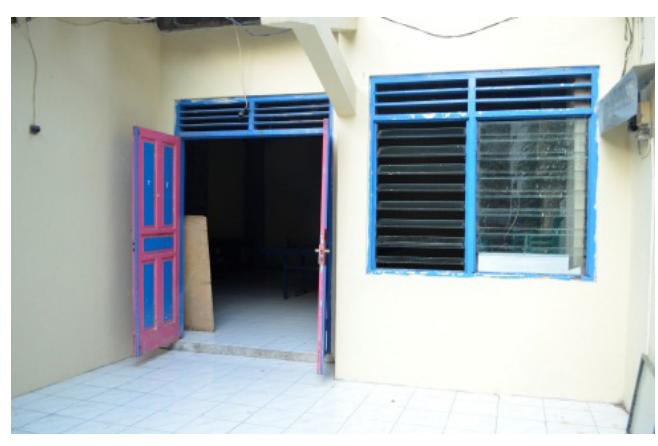

Gambar 2. Kondisi sebelum pengabdian di Pos Lansia Anthurium
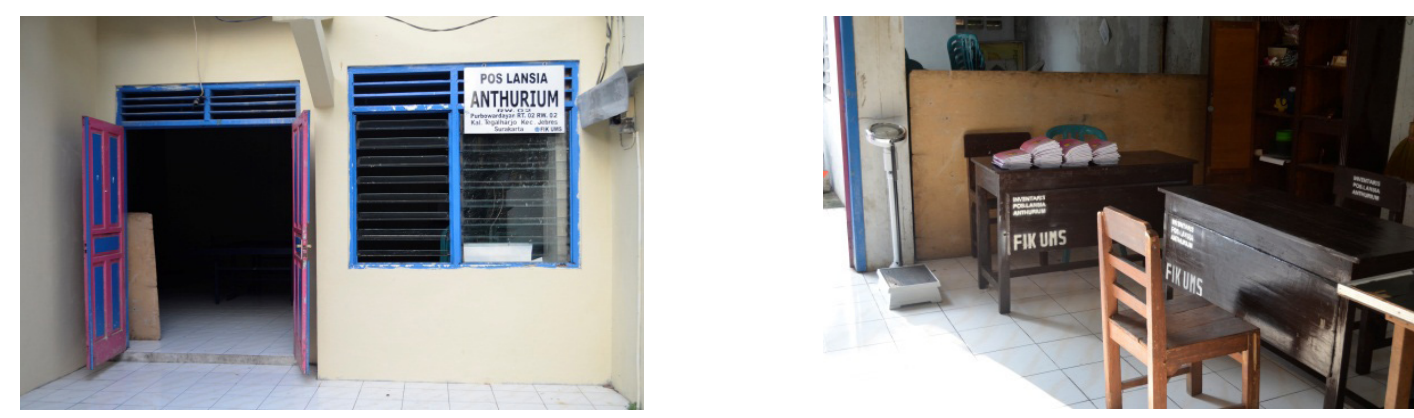

Gambar 3. Kondisi sesudah pengabdian di Pos Lansia Anthurium 
Selanjutnya setelah pengadaan papan nama posyandu, pengadaan sarana pelaksanaan posyandu, kegiatan berikutnya adalah pemberian pendidikan kesehatan. Kegiatan pengabdian yang berupa pendidikan kesehatan dilakukan secara rutin dengan mengikuti jadwal pelaksanaan posyandu yang sudah berjalan. Adapun hasil kegiatan pendidikan kesehatan kesehatan pada Posyandu Anthurium meliputi sebagai berikut :

\section{Pendidikan kesehatan fisioterapi}

Kegiatan ini dilaksanakan oleh tim pengabdian pada Hari Sabtu tanggal 26 Maret 2016 pukul 16.00-17.30 WIB dengan materi tentang osteoarthritis dan pencegahan nyeri punggung bawah (Low Back Pain).
Pada kegiatan ini jumlah lansia yang hadir sebanyak 29 orang, setelah melakukan pendaftaran, kemudian ukur Berat Badan (BB) dan Tinggi Badan (TB), selanjutnya mengukur tekanan darah, kemudian lansia diminta untuk duduk sejenak mengikuti pendidikan kesehatan fisioterapi ini (daftar hadir lansia terlampir). Sambil menikmati Pemberian Makanan Tambahan (PMT) lansia yang disediakan oleh kader. Semua lansia aktif mengikuti pendidikan dan latihan fisioterapi ini. Materi diberikan oleh tim pengabdian dan dibantu oleh delapan orang mahasiswa fisioterapi untuk memandu praktek latihan fisioterapi. Lansia Berikut ini adalah gambar kegiatan pendidikan dan latihan fisioterapi yang diberikan:
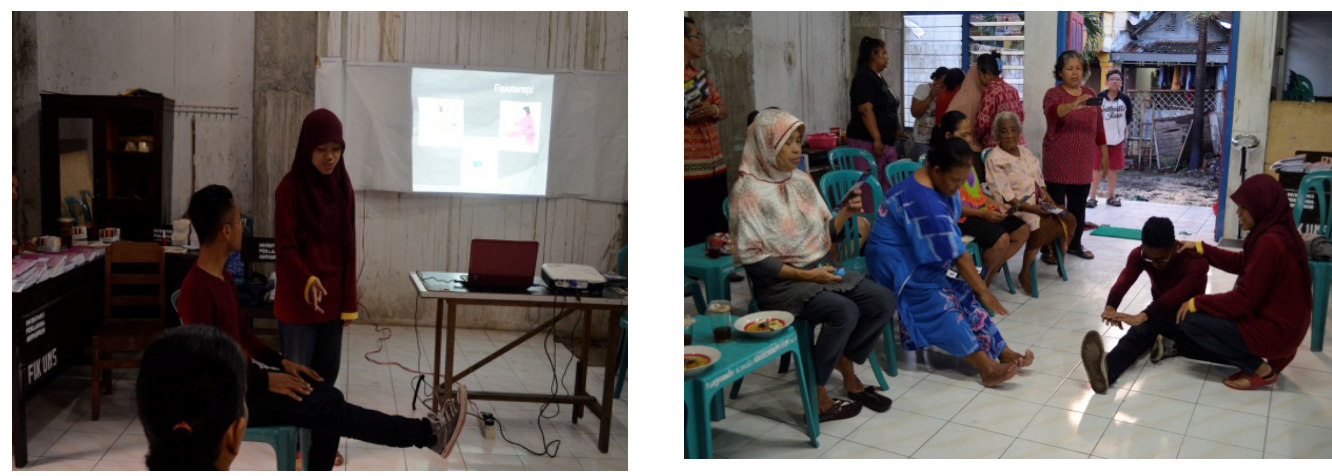

Gambar 4. Kegiatan Pengabdian berupa pendidikan dan pelatihan fisioterapi di Pos Lansia Anthurium

Pada pelatihan ini para peserta lansia sangat antusias dalam mengikutinya. Hal ini terbukti dari seluruh peserta aktif mengikuti gerakan praktek, bertanya, dan untuk mengukur pemahaman peserta tim pengabdian mengadakan kuis tanya jawab. Ternyata sekitar 50\% peserta, sangat aktif untuk menjawab kuis yang disampaikan dan berani untuk mencoba mempraktekkan gerakan yang dilatihkan seperti pada gambar diatas.

\section{Konseling Gizi}

Kegiatan berikutnya pada Pos Lansia Anthurium adalah konseling gizi. Pelaksanaan kegiatan konseling gizi dilaksanakan pada hari Sabtu keempat juga pada pertemuan posyandu lansia, yaitu pada 23 April 2016 jam 16.00- 17.30 WIB. Kegiatan konseling gizi, tetap diawali dengan pelayanan rutin lansia, yaitu mulai pendaftar, cek $\mathrm{BB}$ dan $\mathrm{TB}$, dilanjutkan cek tekanan darah, bila lansia menghendaki diberikan cek darah rutin, yaitu kadar kolesterol, kadar gula darah dan kadar asam urat. Selanjutnya hasil cek darah digunakan sebagai acuan untuk konsultasi gizi, terkait dengan diet makanan yang boleh dikonsumsi, dibatasi dan tidak boleh dikonsumsi bagi penderita hipertensi dan diabetes melitus. Konseling diberikan anggota tim pengabdian yang merupakan ahli gizi, dibantu dengan beberapa mahasiswa dan alat bantu leaflet yang sudah dicetak oleh tim. Adapun kegiatannya digambarkan sebagai berikut : 

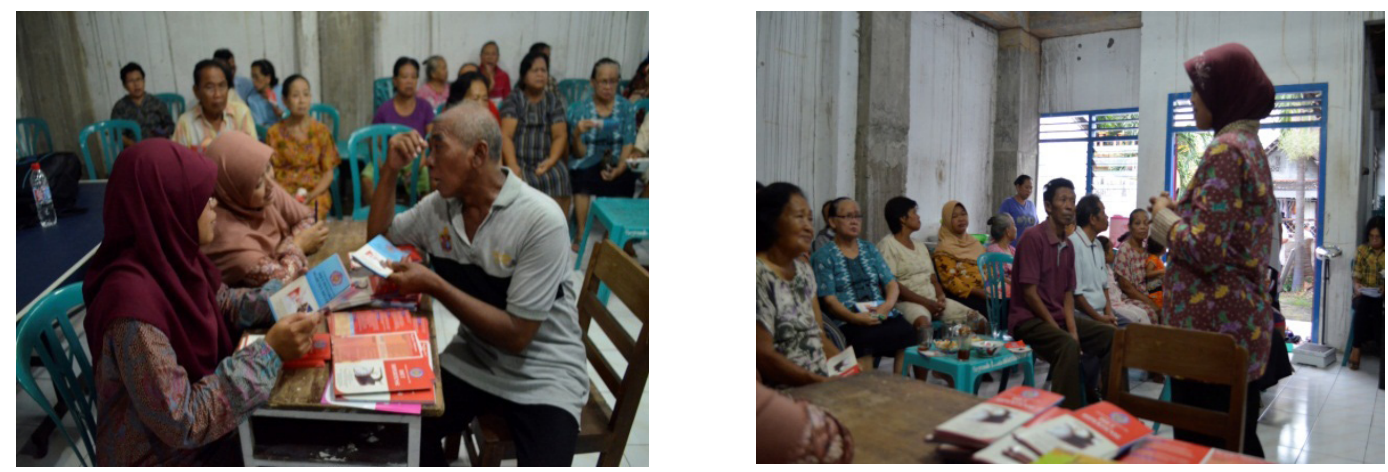

Gambar 8. Kegiatan pengabdian IbM pemberikan konseling gizi dan pendidikan gizi lansia di Pos Lansia Anthurium

Pendidikan kesehatan lansia berikutnya dilakukan melalui pemasangan poster edukasi tentang sembilan langkah hidup sehat lansia, yang meliputi pola makan sederhana, olah raga ringan, hindari makan berlemak, minum susu pencegah osteporosis, mempertahankan berat badan ideal, menghindari asupan garam, berhenti dan menghidari merokok, hindari makanan bersantan dan hindari stress. Poster ini merupakan salah satu media Komunikasi Informasi dan Edukasi (KIE) kesehatan bagi lansia untuk selalu mengingatkan pola hidup sehat. Hal ini juga merupakan penerapan nilai-nilai Islami dalam kehidupan seharihari, terutama membiasakan hidup sehat.

Dengan adanya pengembangan dan variasi kegiatan yang diberikan selama pengabdian pada posyandu, membuat para lansia tidak bosan dan lebih termotivasi untuk selalu datang ke posyandu dan mengontrol kesehatannya, sekaligus dapat memperoleh tambahan informasi dan kegiatan dan tipstips atau anjuran yang bermanfaat untuk memelihara kesehatan lansia.

\section{SIMPULAN DAN SARAN}

\section{Simpulan}

Terwujudnya pengelolaan posyandu Lansia dan kegiatan pelayanan kesehatan lansia yang baik di Pos Lansia Anthurium Tegalharjo Surakarta. Meningkatnya kegiatan posyandu lansia dalam memberikan pelayanan kesehatan bagi lansia di masingmasing wilayah. Meningkatnya keaktifan lansia dalam mengikuti kegiatan posyandu dan terkontrolnya kesehatannya, serta lebih sehat.

\section{Saran}

Berdasarkan temuan dan hasil kegiatan ini, maka perlu dikembangkan kegiatankegiatan yang lebih menarik untuk kehadiran lansia dan fasilitas pos lansia yang mendukung aktifitas kesehatan lansia dalam meningkatkan usia harapan hidup lansia yang lebih sehat, mandiri dan berdaya.

\section{PERSANTUNAN}

Dalam pelaksanaan kegiatan pengabdian ini, kami tidak lepas dari bantuan dan bimbingan beberapa pihak. Ucapan terima kasih kami haturkan kepada Kemenristek Dikti melalui LPPM UMS yang telah memberikan dana sehingga kegiatan ini dapat berjalan dengan baik. Terima kasih kepada ketua Posyandu Lansia Anthurium, Tegalharjo, Surakarta dan segenap kader nya yang telah banyak membantu suksesnya kegiatan ini.

\section{DAFTAR PUSTAKA}

Depkes RI. 2003. Pedoman Pemantauan dan Penilaian Program Kesehatan Usia Lanjut bagi Petugas Kesehatan. Jakarta : Buni Kesehatan Masyarakat, Departemen Kesehatan.

Depkes RI. 2010. Pedoman Puskesmas Santun Lanjut Usia Bagi Petugas Kesehatan, Jakarta: 
Direktorat Bina Kesehatan Komunitas.

Efendi. 2009. Keperawatan Kesehatan Komunitas. Jakarta; Salemba.

Maryati H, Fatoni, A dan T Hexawan. 2013. Gambaran faktor-faktor yang mempengaruhi Lansia tidak mengikuti posynadu lansia di Posyandu Dahlia di 2 Dusun Ngabar Desa Sumberteguh kecamatan Kudu Kabupaten Jombang tahun 2013. Jurnal Metabolisme, Vo. 2 No.3. 2013 ISSN 2338-0438

Mengko VV., Kandou GD,. Massie RGA. 2015. Pemanfaatan Posyandu Lansia di Wilayah Kerja Puskesmas Teling Atas Kota Manado. Jurnal Ilmu Kesehatan Masyarakat Universitas Sam Ratulangi Manado. Vol.5 No.2b.April 2015.ISSN: 2088-3552 